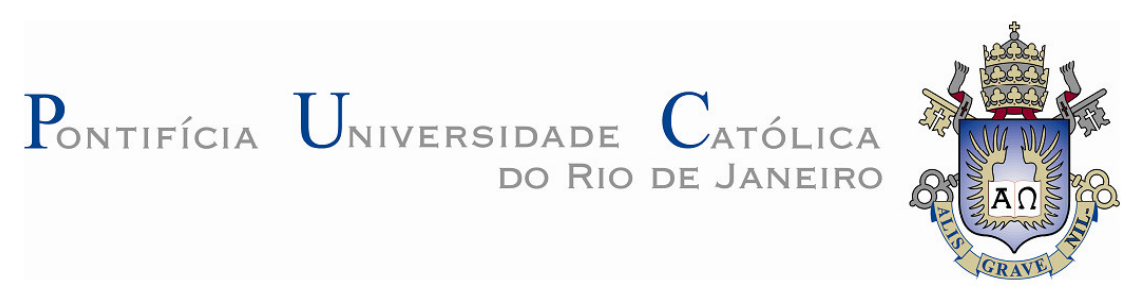

Gino Omar Calderón Vizcarra

\title{
Aplicabilidade de Cinzas de Resíduo Sólido Urbano para Base de Pavimentos
}

Dissertação apresentada como requisito parcial para obtenção do titulo de Mestre pelo Programa de Pós.Graduação em Engenharia Civil do Departamento de Engenharia Civil da PUC-Rio.

Orientadora: Michéle Dal Toé Casagrande Co-orientadora: Laura Maria Goretti da Motta 


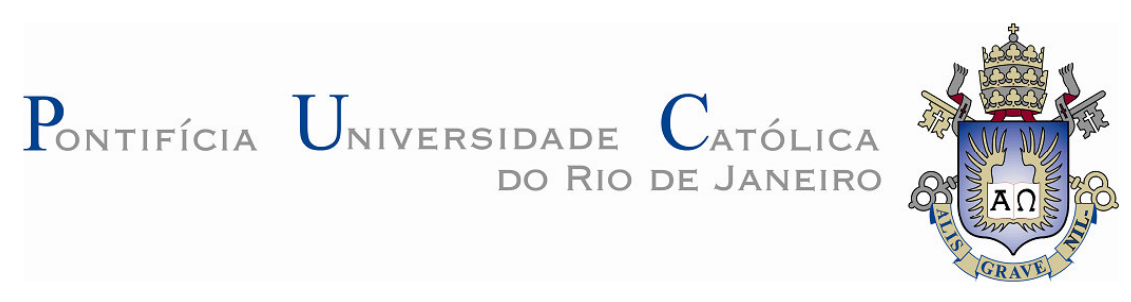

Gino Omar Calderón Vizcarra

\title{
Aplicabilidade de Cinzas de Resíduo Sólido Urbano para \\ Base de Pavimentos
}

\begin{abstract}
Dissertação apresentada como requisito parcial para obtenção do titulo de Mestre pelo Programa de Pós-Graduação em Engenharia Civil do Departamento de Engenharia Civil da PUC.Rio. Aprovada pela Comissão Examinadora abaixo assinada.
\end{abstract}

\author{
Michéle Dal Toé Casagrande \\ Orientadora \\ Departamento de Engenharia Civil - PUC-Rio \\ Laura Maria Goretti da Motta \\ Co-orientadora \\ UFRJ/COPPE
}

Ben-Hur de Albuquerque e Silva IME/RJ

Tácio Mauro Pereira de Campos

Departamento de Engenharia Civil - PUC-Rio

José Eugênio Leal

Coordenador Setorial do Centro

Técnico Científico - PUC-Rio

Rio de Janeiro, 04 de março de 2010 
Todos os direitos reservados. É proibida a reprodução total ou parcial do trabalho sem autorização da universidade, do autor e da orientadora.

\section{Gino Omar Calderón Vizcarra}

Graduou-se em Engenharia Civil pela Universidade Nacional Jorge Basadre Grohmann (Tacna - Peru) em 2000. Trabalhou em projetos e obras no Peru no período 2001-2007. Ingressou no mestrado na Pontifícia Universidade Católica do Rio de Janeiro em 2008, desenvolvendo Dissertação na linha de pesquisa de Geotecnia Experimental aplicada a pavimentos.

Ficha Catalográfica

Calderón Vizcarra, Gino Omar

Aplicabilidade de cinzas de resíduo sólido urbano para base de pavimentos / Gino Omar Calderón Vizcarra; orientadora: Michéle Dal Toé Casagrande ; co-orientadora: Laura Maria Goretti da Motta. - 2010.

120 f. : il. (color.) ; $30 \mathrm{~cm}$

Dissertação (Mestrado)-Pontifícia Universidade Católica do Rio de Janeiro, Departamento de Engenharia Civil, 2010.

Inclui bibliografia

1. Engenharia civil - Teses. 2. Cinzas de incineração de resíduo sólido urbano (RSU). 3. Cinza volante. 4. Cinza de fundo. 5. Base de pavimentos. 6. Misturas solo-cinza. 7. Estabilização de solos. I. Casagrande, Michele Dal Toé. II. Motta, Laura Maria Goretti da. III. Pontifícia Universidade Católica do Rio de Janeiro. Departamento de Engenharia Civil. IV. Título. 
Dedico esta Dissertação à minha avó Carmen Luisa Vizcarra Galindo e à minha prima Diva Daleska Duran Vizcarra 


\section{Agradecimentos}

Talvez esta seja a página mais difícil de ser escrita, pelo simples fato que são tantos para agradecer, tantos para serem apenas lembrados e outros tantos que merecem muito mais que um simples nome citado nestas páginas. Então peço desculpas pelos que por ventura venha esquecer.

À minha avó Carmen Vizcarra, pelo exemplo de vida.

Aos meus pais Rosendo e Rosa, pelo amor e carinho.

À minha família no Peru, em especial à minha tia Elizabeth, pela sua eterna preocupação.

À Pontifícia Universidade Católica do Rio de Janeiro - PUC-Rio, e ao Programa de Pós-Graduação em Engenharia Civil, pela oportunidade de estudar nesta prestigiosa instituição.

À minha orientadora, Professora Michéle Dal Toé Casagrande, com quem sempre me senti à vontade. Obrigado por ter acreditado em mim e sempre me apoiado, motivado, incentivado, compreendido, inspirado e todo o demais tão necessário para poder fazer qualquer empreendimento na vida. Obrigado, além dos ensinamentos e por tudo que consegui aprender.

À Professora Laura Maria Goretti da Motta, por ter me permitido ser mais um dos seus orientados, está por demais falar do seu grande profissionalismo, é para mim um grande privilégio.

À Banca Examinadora pelas sugestões ao presente trabalho.

A todos os colegas do Laboratório de Geotecnia da COPPE/UFRJ, em especial à Mariluce Ubaldo, pelo apoio e acompanhamento da parte 
experimental desta dissertação, assim como ao Bororó e aos Técnicos Washington, Thiago, Allan, Leandro, Roberto e Rodrigo pela ajuda nas moldagens e preparação das amostras. Ao Carlinhos, Serginho, Maria da Gloria, Rosângela, Sandra e Vera por terem me considerado como parte da família COPPE.

Aos professores da PUC-Rio, pelas aulas ministradas, e pelos quais guardo grande respeito, apreço e admiração.

A todos os colegas das turmas 2007.2, 2008.1, 2008.2 e 2009.1 com os quais compartilhei as aulas.

Ao Gerson Alves Bastos, pela sua amizade, e por ter compartilhado as muitas horas de estudo na sala 607.C.

Ao Carlos Aguilar, pela sua generosa acolhida na minha imprevista chegada ao Rio de Janeiro.

Ao Luis Paullo, Iván Aguilar e Julio Bizarreta, pelo simples e aventureiro convívio no Alto Gávea.

À Alejandra Cruz, Bruno Carvalho, Iván Benites, Rocío Pérez, Juliana e Nithson, pela sua amizade.

À Lucianna Szeliga, pelo acompanhamento e realização de parte dos ensaios de caracterização.

À Usina Verde S.A. na pessoa do Eng. Jorge Nascimento, pelo fornecimento das cinzas utilizadas neste estudo.

À Rita de Cassia, pelo constante apoio e preocupação.

À CAPES e ao CNPq, pela oportunidade e financiamento desta pesquisa. 


\section{Resumo}

Vizcarra, Gino Omar Calderón; Casagrande, Michéle Dal Toé; Motta, Laura Maria Goretti. Aplicabilidade de Cinzas de Resíduo Sólido Urbano para Base de Pavimentos. Rio de Janeiro, 2010. 120 p. Dissertação de Mestrado. Departamento de Engenharia Civil, Pontifícia Universidade Católica do Rio de Janeiro.

Este estudo apresenta a caracterização de cinzas obtidas da incineração de Resíduo Sólido Urbano (RSU) em usina geradora de energia elétrica, tendo como objetivo avaliar sua aplicabilidade em camadas de base de pavimentos rodoviários, através da mistura destas cinzas a um solo argiloso não.laterítico regional. Foram realizados ensaios de caracterização química, física e mecânica, para o solo puro e para o mesmo com a adição de diferentes teores de cinzas (20 e 40\%), bem como o dimensionamento mecanístico.empírico para uma estrutura típica de pavimento. As misturas com inserção de cinzas apresentaram um comportamento mecânico compatível com as exigências de um pavimento de baixo volume de tráfego. A cinza volante diminuiu a expansibilidade do material, apresentando um aumento substancial no valor de CBR. Os resultados obtidos demonstram que o módulo resiliente do solo em estudo é dependente da tensão desviadora e que a inserção de cinza volante e cura prévia da mistura dobram o valor do módulo resiliente, o que resulta em diminuição da espessura da camada de base em comparação ao solo puro, para um mesmo nível de carregamento e mesmos critérios de dimensionamento. Os resultados obtidos foram satisfatórios, sendo dependentes do teor e do tipo de cinza utilizado, ressaltando o emprego positivo da cinza volante de RSU para aplicação em camadas de base de pavimentos rodoviários, minimizando problemas atuais de disposição de resíduos em lixões e aterros sanitários, dando um fim mais nobre a este material. Ressalta.se que estudos sobre a utilização deste tipo de resíduos em pavimentação são raros no país e esta pesquisa agrega um conhecimento exploratório do potencial de sua aplicabilidade.

\section{Palavras-chave}

Cinzas de incineração de resíduo sólido urbano (RSU); cinza volante; cinza de fundo; base de pavimentos; misturas solo.cinza; estabilização de solos. 


\section{Abstract}

Vizcarra, Gino Omar Calderón; Casagrande, Michéle Dal Toé (Advisor); Motta, Laura Maria Goretti (Co-advisor). Applicability of Municipal Solid Waste Ash for Pavements Base. Rio de Janeiro, 2010. 120 p. MSc. Dissertation - Departamento de Engenharia Civil, Pontifícia Universidade Católica do Rio de Janeiro.

This study presents the characteristics of Municipal Solid Waste (MSW) incineration ash obtained from electric energy generation place, to evaluate the MSW ash applicability road base as a pavement layer through the ash mixture with a non.lateritic regional clay soil. Chemical, physical, mechanical tests and the mechanistic.empirical design for a typical pavement structure were carried out on the pure soil and also in the soil mixture with the addition of different ash content (20 and 40\%). The addition of MSW ash had a consistent mechanical behavior to be used on low traffic volume road pavements. Fly ash reduced the expansion of the material, showing a substantial increase in the CBR value. The results show that the resilient modulus of soil is dependent on the deviator stress and the fly ash addition with a mixture cure increase the value of resilient modulus, which is revealed by the decrease in thickness of the base layer, compared to pure soil for the same level of loading and the same design requirements. The results were satisfactory, being dependent on the content and type of ash used, highlighting the positive work of MSW fly ash for use in base road pavement layers, minimizing the current problems of waste disposal in landfills, giving a noble use for this material. It is noteworthy that studies on the use of such waste in pavements are rare and this research adds to an exploratory knowledge of its potential applicability.

\section{Keywords}

Municipal solid waste (MSW) incineration ash; fly ash; bottom ash; pavements base; soil.ash mixtures; soil stabilization. 


\section{Sumário}

1 Introdução 19

$\begin{array}{lr}1.1 \text { Relevância e justificativa da pesquisa } & 19\end{array}$

$\begin{array}{ll}1.2 \text { Objetivos } & 20\end{array}$

$\begin{array}{ll}1.3 \text { Organização da Dissertação } & 21\end{array}$

2 Revisão Bibliográfica $\quad 22$

2.1 Estabilização de Solos

2.1.1 Estabilização Mecânica 23

2.1.2 Estabilização Física $\quad 24$

2.1.3 Estabilização Química 25

2.1.3.1 Solo.cimento 26

2.1.3.2 Solo.cal 28

2.2 Solo.cinza de carvão $\quad 30$

2.2.1 Aplicações do Solo.cinza de carvão 31

2.2.2 Utilização de cinzas de carvão na Pavimentação 33

$\begin{array}{ll}2.3 \text { Solo.cinza de RSU } & 34\end{array}$

$\begin{array}{ll}2.4 \text { Utilização de resíduos em Pavimentação. } & 37\end{array}$

2.5 Dimensionamento de pavimentos asfálticos $\quad 40$

2.5.1 Módulo de Resiliência 41

2.5.2 Sistema computacional SisPav 43

2.6 Solos expansivos $\quad 44$

2.7 Considerações sobre a revisão bibliográfica 45

3 Programa Experimental $\quad 46$

3.1 Materiais 46

$\begin{array}{ll}3.1 .1 \text { Solo } & 46\end{array}$

3.1.2 Cinza Volante e Cinza de Fundo $\quad 47$

3.1.2.1 Produção das cinzas de RSU 48

3.1.2.2 Processo de incineração 48

3.1.3 Misturas Solo/Cinza $\quad 53$

3.2 Métodos e Procedimentos de Ensaio 54

3.2.1 Ensaios de caracterização física 55

3.2.1.1 Massa Especifica Real dos Grãos $\quad 55$

3.2.1.2 Limites de Atterberg $\quad 55$

3.2.1.3 Análise granulométrica 56

3.2.1.4 Ensaio de MCT 56 
3.2.2 Ensaios químicos $\quad 62$

3.2.2.1 Composição Química 62

3.2.2.2 Teor de Matéria Orgânica 63

3.2.2.3 Solubilização e Lixiviação 64

3.2.3 Ensaios de Caracterização Mecânica 65

3.2.3.1 Ensaio de Compactação 65

3.2.3.2 Ensaio de Modulo de Resiliência 66

3.2.3.3 Ensaio de CBR

3.2.4 Dimensionamento de pavimento típico 74

3.3 Considerações sobre o Programa Experimental 76

4 Apresentação e Discussão dos Resultados 77

4.1 Ensaios de caracterização física 77

4.1.1 Densidade Real dos Grãos $\quad 77$

4.1.2 Limites de Atterberg $\quad 79$

4.1.3 Análise granulométrica 83

4.1.4 Classificação SUCS 85

4.1.5 Classificação AASHTO $\quad 85$

4.1.6 Classificação MCT 86

4.2 Ensaios químicos $\quad 87$

4.2.1 Composição Química $\quad 87$

4.2.2 Teor de Matéria Orgânica 90

4.2.2 Ensaio de Lixiviação 92

4.2.2 Ensaio de Solubilização 93

4.3 Ensaios de Caracterização Mecânica 95

4.3.1 Ensaio de Compactação 95

4.3.2 Ensaio de Modulo de Resiliência 99

4.3.2.1 Influência do tempo de cura e atraso na compactação no modulo resiliente 103

4.3.2.2 Influência do número de ciclos de carregamento N no modulo resiliente 106

$\begin{array}{ll}\text { 4.3.3 Ensaio de CBR } & 106\end{array}$

4.4 Dimensionamento de pavimento típico 107

4.5 Considerações sobre a apresentação e discussão dos resultados 110

5 Considerações Finais 111

5.1 Conclusões 111

5.2 Sugestões para pesquisas futuras 112

$\begin{array}{ll}\text { Bibliografia } & 114\end{array}$ 


\section{Lista de Figuras}

Figura 2.1. Efeito do tempo sobre solo estabilizado com CVRSU, cal e cimento

Figura 2.2. Tensões numa estrutura de pavimento 40

$\begin{array}{ll}\text { Figura 3.1. Solo não.laterítico estudado } & 47\end{array}$

Figura 3.2. Cinza Volante de RSU. $\quad 47$

Figura 3.3. Cinza de Fundo de RSU. 47

Figura 3.4. Composição do RSU da Usina Verde (FONTES, 2008) 48

Figura 3.5. Segregação de materiais para reciclagem 50

Figura 3.6. Processo de geração de energia elétrica na Usina Verde 51

Figura 3.7. Etapas do processo de incineração de RSU na Usina Verde S/A 52

Figura 3.8. Compactador MCT da COPPE/UFRJ usado nesta pesquisa. $\quad 58$

Figura 3.9. Cápsulas imersas para o ensaio de perda por imersão

imediatamente após imersão. $\quad 60$

Figura 3.10. Perda por imersão do solo deste estudo após 24 horas de imersão.

Figura 3.11 Equipamento de EDX do LABEST da COPPE/UFRJ usado nesta pesquisa.

Figura 3.12. Equipamento mecânico para compactação de corpos de prova.

Figura 3.13. Molde tripartido 10 × $20 \mathrm{~cm}$, para compactação de corpos de prova.

Figura 3.14. Esquema llustrativo do Equipamento de Ensaios Triaxiais de Carga Repetida.

Figura 3.15. Equipamento de Ensaios Triaxiais de Carga Repetida da COPPE/UFRJ usado nesta pesquisa.

Figura 3.16. Tomada de leitura de deformação no ensaio CBR na amostra desta pesquisa.

Figura 3.17. Fotografia do Equipamento utilizado para obtenção do CBR nesta pesquisa.

Figura 3.18. Estrutura do pavimento típico adotada para a análise mecanística.empírica.

Figura 3.19. Fluxograma do método integrado de análise e dimensionamento de pavimentos asfálticos do SisPav.

Figura 4.1. Variação da densidade real dos grãos com o teor de cinza 
volante neste estudo.

Figura 4.2. Variação da densidade real dos grãos com o teor de cinza de fundo neste estudo.

Figura 4.3. Variação dos Limites de Atterberg com o teor de cinza volante neste estudo.

Figura 4.4. Variação do Índice de Plasticidade com o teor de cinza volante neste estudo.

Figura 4.5. Variação dos Limites de Atterberg com o teor de cinza de fundo deste estudo.

Figura 4.6. Variação do Índice de Plasticidade com o teor de cinza de fundo deste estudo.

Figura 4.7. Efeito da estabilização com cinza volante sobre a plasticidade de solos estabilizados.

Figura 4.8. Efeito da cinza volante sobre o índice de plasticidade e limite de contração linear de solos de Degirmenlik e Tuzla, estabilizados com cinza volante.

Figura 4.9. Curvas Granulométricas do solo, cinza de fundo e cinza volante deste estudo.

Figura 4.10. Curvas Granulométricas do solo, cinza volante e misturas do solo com $20 \%$ e $40 \%$ de cinza volante deste estudo.

Figura 4.11. Granulometria do solo, cinza de fundo e misturas do solo com $20 \%$ e $40 \%$ de cinza de fundo deste estudo.

Figura 4.12. Classificação MCT para o solo puro.

Figura 4.13. Curvas de compactação de solo e misturas com $20 \%$ e $40 \%$ de cinza volante deste estudo.

Figura 4.14. Variação da Massa específica aparente seca com o teor de cinza volante.

Figura 4.15. Variação do teor de umidade ótimo com o teor de cinza volante deste estudo.

Figura 4.16. Curvas de compactação de solo e misturas com $20 \%$ e $40 \%$ de cinza de fundo deste estudo.

Figura 4.17. Variação da Massa específica aparente seca com o teor de cinza de fundo deste estudo.

Figura 4.18. Variação do teor de umidade ótimo com o teor de cinza de fundo deste estudo.

Figura 4.19. Curva de compactação das misturas solo/cinza pesada. 
Figura 4.20. Gráfico 3D do modelo composto do Módulo Resiliente do solo puro deste estudo.

Figura 4.21. Gráfico 3D do modelo composto do Módulo Resiliente da mistura S80/CV20 deste estudo.

Figura 4.22. Gráfico 3D do modelo composto do Módulo Resiliente da mistura S60/CV40 deste estudo.

Figura 4.23. Gráfico 3D do modelo composto do Módulo Resiliente da mistura S80/CF20 deste estudo.

Figura 4.24. Gráfico 3D do modelo composto do Módulo Resiliente da mistura S60/CF40 deste estudo.

Figura 4.25. Variação do Módulo Resiliente vs. tensão desviadora da mistura S60/CV40 com o tempo de atraso e o tempo de cura deste estudo. 104 Figura 4.26. Variação do Módulo Resiliente vs. tensão confinante da mistura S60/CV40 com o tempo de atraso e o tempo de cura deste estudo. 105 Figura 4.27. Variação do Módulo Resiliente vs. tensão desviadora da mistura S60/CV40 com o teor de umidade deste estudo.

Figura 4.28. Variação do Módulo Resiliente vs. tensão confinante da mistura S60/CV40 com o teor de umidade deste estudo.

Figura 4.29. Estrutura do pavimento adotada.

Figura 4.30. Dados do clima utilizado para o programa SisPav.

Figura 4.31. Variação das espessuras de camada em função do período de projeto. 


\section{Lista de Tabelas}

Tabela 2.1 - Combinações de Material/Aplicação em pavimentação.

Tabela 2.2 - Tensões numa estrutura de pavimento

Tabela 2.3 - Modelos de comportamento tensão.deformação de solos observados no Brasil.

43

Tabela 3.1 - Símbolos referentes a cada material.

53

Tabela 3.2 - Valores típicos de c' para diferentes granulometrias de solos. $\quad 58$

Tabela 3.3 - Valores típicos de d' para diferentes granulometrias de solos $\quad 59$

Tabela 3.4 - Níveis de tensões aplicados na fase de condicionamento 70

Tabela 3.5 - Níveis de Tensões utilizados durante o Ensaio Triaxial

Dinâmico especificado pela COPPE

71

Tabela 4.1 - Resultados do ensaio de densidade real dos grãos para o solo, cinza volante e misturas.

77

Tabela 4.2 - Resultados do ensaio de densidade real dos grãos para o solo, cinza de fundo e misturas.

Tabela 4.3 - Resultados dos ensaios de Limites de Atterberg para o solo e misturas com cinza volante.

Tabela 4.4 - Resultados dos ensaios de Limites de Atterberg para o solo e misturas com cinza de fundo neste estudo.

80

Tabela 4.5 - Resultados das análises granulométricas. 84

Tabela 4.6 - Índices para classificação SUCS. 85

Tabela 4.7 - Índices para classificação AASHTO. 85

Tabela 4.8 - Composição química do solo deste estudo realizado em duas amostras do mesmo

Tabela 4.9 - Composição química de três argilas de comportamento não.lateritico.

Tabela 4.10 -. Análise química semiquantitativa de óxidos para três solos residuais e rocha alterada.

Tabela 4.11 - Composição química da Cinza Volante de RSU, mistura (S60/CV40) e Cinza Volante de Carvão

Tabela 4.12 - Composição química da Cinza de Fundo de RSU mistura (S60/CV40) e Cinza de Fundo de Carvão.

Tabela 4.13 - Teor de matéria orgânica do solo, da cinza de fundo e da cinza volante deste estudo.

Tabela 4.14 - teor de matéria orgânica da mistura S80/CV20, S60/CV40, 
S80/CF20 e S60/CF40 deste estudo.

Tabela 4.15 - Resultados analíticos: Lixiviado - Parâmetros Inorgânicos 92

Tabela 4.16 - Resultados analíticos: Lixiviado - Parâmetros Orgânicos 92

Tabela 4.17 - Resultados analíticos: Solubilizado - Parâmetros Inorgânicos 93

Tabela 4.18 - Resultados analíticos: Solubilizado - Parâmetros Orgânicos 94

Tabela 4.19 - Valores de umidade ótima e massa específica aparente seca máxima.

Tabela 4.20 - Valores dos coeficientes do modelo composto para cada material ou mistura desta pesquisa.

Tabela 4.21 - Variação dos coeficientes do modelo composto com o atraso na compactação e o tempo de cura para a mistura S60/CV40 deste estudo. 104 Tabela 4.22 - Valores de expansão aos 4 dias de imersão, sem tempo de cura e três dias de atraso na compactação após hidratação. 107 $\begin{array}{ll}\text { Tabela } 4.23 \text { - Valores de CBR } & 107\end{array}$ $\begin{array}{ll}\text { Tabela } 4.24 \text { - Dados do tráfego. } & 108\end{array}$ Tabela 4.25 - Espessura de camada em função do período de projeto para cada tipo de solo ou mistura. 


\section{Lista de Abreviaturas}

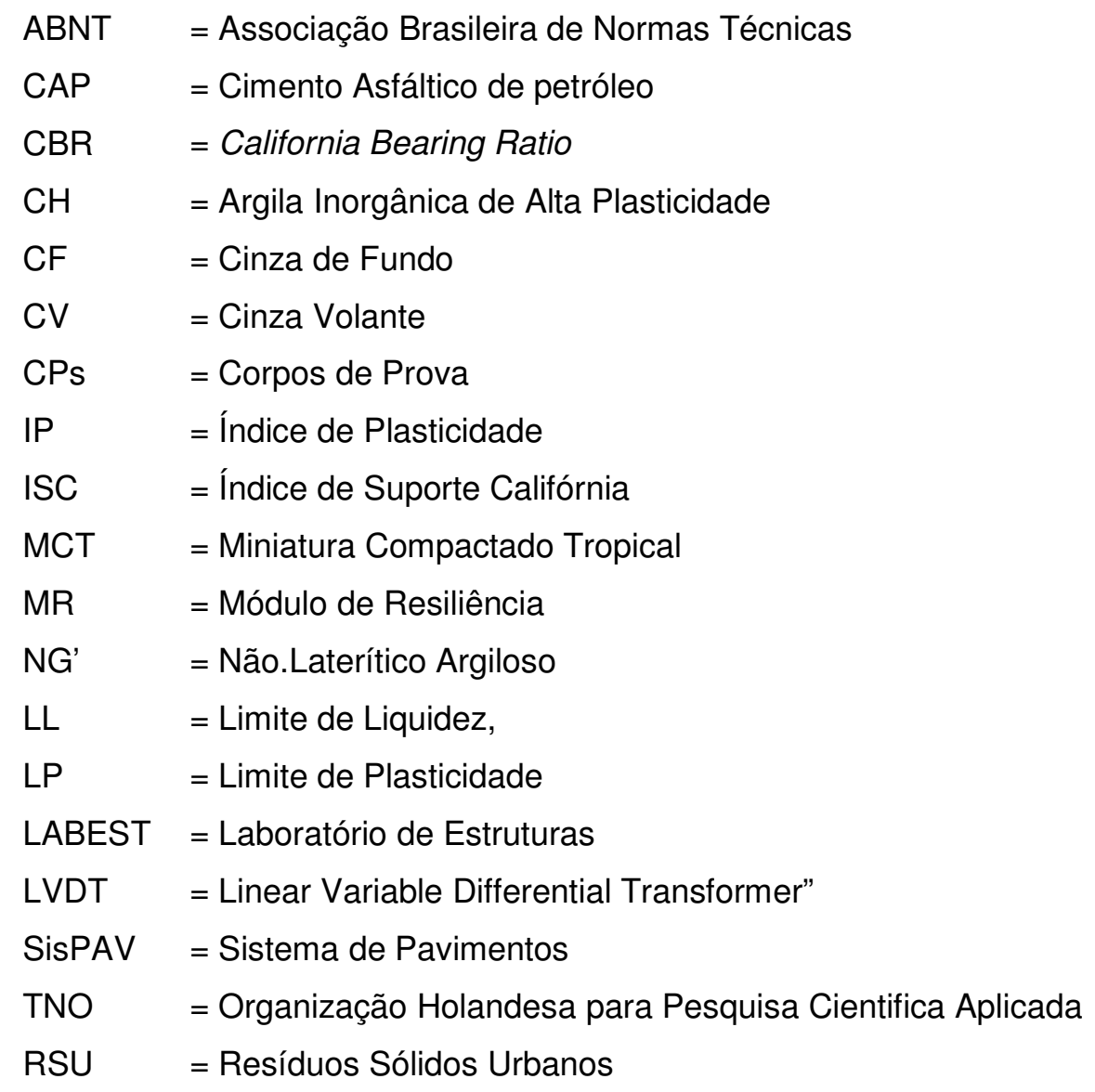




\section{Lista de Símbolos}

$$
\begin{aligned}
& \text { wótm = umidade ótima de compactação } \\
& \text { ydmáx = peso específico seco aparente máximo } \\
& \gamma d \quad=\text { massa específica seca } \\
& \mathrm{W} \quad=\text { umidade } \\
& \mathrm{MR} \quad=\text { módulo resiliente } \\
& \text { od = tensõe desviadora } \\
& \text { б3 = tensão confinante } \\
& \mathrm{E} \quad=\text { expansão } \\
& \mathrm{h}=\text { altura final do corpo de prova. } \\
& \text { hi }=\text { altura inicial do corpo de prova. } \\
& \mathrm{N}_{\mathrm{f}} \quad \text { = vida de fadiga } \\
& \text { Et = deformação específica de tração } \\
& \text { Gs = massa específica real dos grãos } \\
& \text { c'= coeficiente do ensaio MCT } \\
& \text { d' = coeficiente angular do ramo seco da curva de compactação } \\
& \text { referente a energia de } 12 \text { golpes no ensaio Mini.MCV } \\
& \mathrm{e}^{\prime} \quad \text { = coeficiente do ensaio MCT } \\
& \mathrm{Pi}=\text { perda de massa por imersão no ensaio MCT } \\
& k 1, k 2, k 3=\text { coeficientes do modelo Composto } \\
& \text { e } \quad=\text { espessura } \\
& \mathrm{V} \quad=\text { coeficiente de Poisson } \\
& \mathrm{SiO}_{2} \quad=\text { Sílica } \\
& \mathrm{Al}_{2} \mathrm{O}_{3} \quad=\text { Alumina } \\
& \mathrm{Fe}_{2} \mathrm{O}_{3} \quad=\text { Hematita } \\
& \mathrm{SO}_{3} \quad=\text { anidrido sulfúrico } \\
& \mathrm{CaO}=\text { óxido de cálcio } \\
& \mathrm{Cl}=\text { cloro } \\
& \mathrm{TiO}_{2}=\text { Dióxido de titânio } \\
& \mathrm{K}_{2} \mathrm{O}=\text { Óxido de potássio } \\
& \mathrm{P}_{2} \mathrm{O}_{5} \quad=\text { Pentóxido de fósforo } \\
& \mathrm{ZnO}=\text { Óxido de zinco } \\
& \mathrm{Cr}_{2} \mathrm{O}_{3}=\text { Óxido de crômio (III) } \\
& \mathrm{MnO}=\text { Óxido de manganês (II) } \\
& \text { SrO = Óxido de estrôncio }
\end{aligned}
$$




$\begin{array}{ll}\mathrm{ZrO}_{2} & =\text { Óxido de zircônio } \\ \mathrm{CuO} & =\text { Óxido de cobre (II) } \\ \mathrm{PbO} & =\text { Óxido de chumbo (II) } \\ \mathrm{AC} & =\text { Actínio } \\ \mathrm{Br} & =\text { Bromo } \\ \mathrm{Rb}_{2} \mathrm{O} & =\text { Óxido de Rubídio } \\ \mathrm{Y}_{2} \mathrm{O}_{3} & =\text { Óxido de ítrio (III) } \\ \mathrm{MgO}_{\mathrm{Ni}} & =\text { Óxido de magnésio } \\ \mathrm{V}_{2} \mathrm{O}_{5} & =\text { Níquel } \\ \mathrm{NbO} & =\text { Pentóxido de vanádio } \\ \mathrm{BaO} & =\text { Monóxido de nióbio } \\ & =\text { Óxido de bário }\end{array}$

